\title{
GIS-BASED DETECTION AND QUANTIFICATION OF PATCH-BOUNDARY PATTERNS FOR IDENTIFYING LANDSCAPE MOSAICS
}

\author{
HARdT, E. ${ }^{1,2^{*}}$-De PABlo, C. L. ${ }^{3}$-De Agar, P. M. ${ }^{3}$-Dos SANtos, R. F. ${ }^{2,4}$-Pereira-Silva, E. F. ${ }^{4,5}$ \\ ${ }^{1}$ Department of Environmental Sciences, Federal University of São Paulo \\ Rua São Nicolau, 210, 09913-030 Diadema, Brazil \\ (phone: +55-11-4044-0500 ramal 3470) \\ ${ }^{2}$ Laboratory of Environmental Planning, Campinas State University \\ Campinas, Brazil \\ ${ }^{3}$ Department of Ecology, Complutense University of Madrid \\ Madrid, Spain \\ ${ }^{4}$ Department of Ecology, University of São Paulo \\ São Paulo, Brazil \\ ${ }^{5}$ Center of Natural and Human Sciences, Federal University of $A B C$ \\ São Bernardo do Campo, Brazil \\ *Corresponding author \\ e-mail: elisa.hardt@unifesp.br \\ (Received $24^{\text {th }}$ Sep 2017; accepted $5^{\text {th }}$ Feb 2018)
}

\begin{abstract}
The study of boundaries between patches allows us to understand the complexity of landscape interactions, especially those involved in the anthropic use of natural resources, which is a common source of environmental problems when harnessing landscape services. The study of the relationships between those two elements makes it possible to identify distinct homogeneous environmental areas in which the same ecological interactions occur. These areas are the mosaics that make up a landscape. This paper presents a GIS-based procedure to identify and quantify the boundaries of land use/cover patches and to record those data in matrices of patches by boundaries. These matrices, by means of a multivariate analysis, allow us to recognize landscape mosaics. This semi-automated procedure contributes to making the concept of landscape mosaics operative and enabling its application to landscape management. To exemplify its possibilities, we tested three alternatives for quantifying boundary measures: presence/absence, frequency and length. They each describe interactions with different details and provide different nuances in interpretations of landscape organization. In the study case, the frequency data provided a more easily understandable interpretation of the mosaic identification and characterization of landscape heterogeneity because these data are less conditioned by the spatial distribution, size or length of rare boundaries. Irrespective of the boundary measure used, a large central mosaic is always identified, highlighting the influence of landscape homogeneity and fragmentation on mosaic identification and the robustness of the tested procedure.
\end{abstract}

Keywords: landscape ecology, landscape evaluation, landscape model, land use and cover, spatial analysis

\section{Introduction}

Landscape ecology provides a suitable set of concepts and knowledge for studying the ecological functioning of landscape pattern and its relationship with human society (Wiens et al., 2007; Kirchhoff et al., 2013; Bastian et al., 2015). Landscape pattern is the central topic in landscape ecology, as it is both consequence and cause of 
ecological functioning (Forman and Godron, 1981; Turner, 1989) on which the supply of environmental services is based (MEA, 2005; TEEB, 2010). The study of landscape pattern, being directly related to functioning, is therefore crucial in ecosystem services conservation planning and management (Forman, 1990; De Groot et al., 2010; Frank et al., 2012; Maes et al., 2013; Martín de Agar et al., 2016).

Landscape pattern is usually studied as spatial distributions of patches and boundaries (Forman and Godron, 1981; Urban et al., 1987). The relationships between the two allow us to understand and interpret the ecological functioning of landscapes (Turner, 1989; Forman, 1990; Cantwell and Forman, 1993; Cadenasso et al., 2003; Roldán et al., 2003; Hersperger, 2006). Landscape spatial heterogeneity based on the joint spatial pattern of these elements is referred to as landscape mosaics (Forman, 1995; Roldán et al., 2003; Hersperger, 2006). This is a central issue in ecology and has special scientific relevance because it permits understandings of how patches and boundaries interact with each other to define zones with similar ecological interactions. These zones are the basis of ecological planning and service assessments (Martín de Agar et al., 2016).

Mosaics are defined as sets of patches with a similar pattern of boundaries (Roldán et al., 2003). Accordingly, a landscape comprises different mosaics (Roldán et al., 2006; De Pablo et al., 2012), on which patches have homogeneous ecological functioning, and the boundaries denote places where this functioning change, including the type, direction and magnitude of interactions taking place among the former (Margalef, 1979; Wiens et al., 1985; Gosz, 1991; Wiens, 2002; Cadenasso et al., 2003; Peters et al., 2006). Such mosaic-based studies of landscape integrate information provided by patches, boundaries and the relationships between them (Roldán et al., 2003; Peters et al., 2006). The usefulness of this approach has been demonstrated from both academic (Roldán et al., 2006; De Pablo et al., 2010) and applied perspectives (Hardt et al., 2013; Bertolo et al., 2015; Martín de Agar et al., 2016). Studies have been undertaken on the complexity of interactions between natural resources and anthropic uses in the Atlantic Forest in São Paulo, Brazil (Hardt et al., 2013; Bertolo et al., 2015), and in a traditional mountainous agrarian, livestock and forestry cultural landscape in Madrid, Spain (Roldán et al., 2006; De Pablo et al., 2010; Martín de Agar et al., 2016). Numerous techniques have been developed to identify boundaries from spatial data (Jacquez et al., 2000, 2008; Fagan et al., 2003; Fortin and Dale, 2005; Banerjee et al., 2015). At present, many landscape studies, especially those with applied objectives, are based on land cover or land use maps. On those maps, it is easy to recognize the boundaries from the edges between patches (Rescia et al., 1997; Metzger and Müller, 1996; Roldán et al., 2003). However, to identify and map a mosaic as a set of patches with similar boundaries, additional techniques are needed to determine the spatial interactions between the two. It is also necessary to build a matrix of patches by boundaries in order to collect the spatial relationships between both, on which mosaics recognition is based.

The goal of this paper is to develop a Geographical Information System (GIS) procedure for identifying and recording boundaries of individual landscape patches and for building matrices of patches $\times$ boundaries. This paper details this GIS procedure coupled to the multivariate analysis needed to identify and map landscape mosaics that synthesize the spatial heterogeneity. A case study in an Atlantic Forest area is used to illustrate the results obtained in each procedure stage. The procedure is based on that of Roldán et al. (2003) that worked with a non-automated technique and was applied by 
Hardt et al. (2013) to landscape management. The novelty of this paper is the semiautomatic recording of boundary measures (presence/absence, frequencies and lengths) for each patch obtained from raster or vector land use/cover maps.

It is primarily a technical issue, but the developed tool provides a basis for facilitating the use of current techniques for mosaic recognition in landscape studies. It is an innovative application of a remote sensing methodology to tackle a common Brazilian environmental problem: the increase in tropical forest interaction complexity with anthropic uses. This understanding aids, for example, in the conservation, planning and management of natural resources in regions that face complex environmental issues.

Although the procedure described above has already been applied in some studies (Hardt et al., 2013; Bertolo et al., 2015; Martín de Agar et al., 2016), this is the first time that the unpublished developed procedure is presented step by step for easy application to other landscapes, thus allowing the landscape mosaic identification technique to be well known by scientists, planners and managers involved in nature conservancy.

\section{Materials and methods}

\section{The case study}

The methodological procedure was originally developed for a case study in an Atlantic Forest landscape in Serra do Japi, State of São Paulo, Brazil (Appendix A). The mountainous area is covered by a semi-deciduous forest, Red-Yellow Latosols (Oxisols) predominate, and the climate is seasonal, with a hot and rainy season and a dry and cold season (Morelatto, 1992).

\section{Methodological procedure}

The procedure developed for identifying and mapping boundaries and mosaics consists of three stages that are described in detail in the next subsections.

\section{Stage 1 - Identifying boundaries}

Boundaries were recognized using ArcGIS on a land use/cover map created by photointerpretation of orthophotos from 2005 (scale 1:25,000). The procedure consists of identifying the common edges between adjoining patches. Different pairs of adjacent land use/cover identify the differing boundaries, which are each stored in separate layers. Using the land use/cover layers in a polygon vector format as inputs, the layers of the patch edges are generated by just dilating the polygons of land use/cover (Fig. 1I; Tables $1 A-I$ and $B-I)$.

There are two alternatives depending on whether these layers will be stored in raster or vector format. For the former, the layers of the edges are converted to raster format and are then reclassified as prime numbers (Fig. 1-II; Table 1A-II). Subsequently, all possible pairs of layers that represent the different land uses/covers are multiplied (Fig. 1-III; Table 1A-III). Because these are codified as prime numbers, the result of each multiplication is unique, and each multiplication represents a single type of boundary among the existing uses in the study area. All layers obtained by multiplication are then added to generate a raster layer with all boundaries. 
To draw a boundary map in vector format, the boundary layers of all possible pairs of land uses/covers, as obtained in Table $1 B-I I$, are directly overlaid. The denomination of the boundaries is then included, and the data are merged into a single file (Table 1B-III).

\section{Stage 2 - Drawing up patches $\times$ boundaries matrices}

In this stage, the types of boundaries for each patch of land use/cover are identified and organized in a matrix using the same procedure for both raster and vector formats. Boundary type is recorded as i) presence-absence, which represents whether a boundary type is or is not present, ii) frequency, which is the number of segments of a boundary type and iii) length, which is the sum of the segment lengths of a boundary type.

\section{Buffer Wizard}

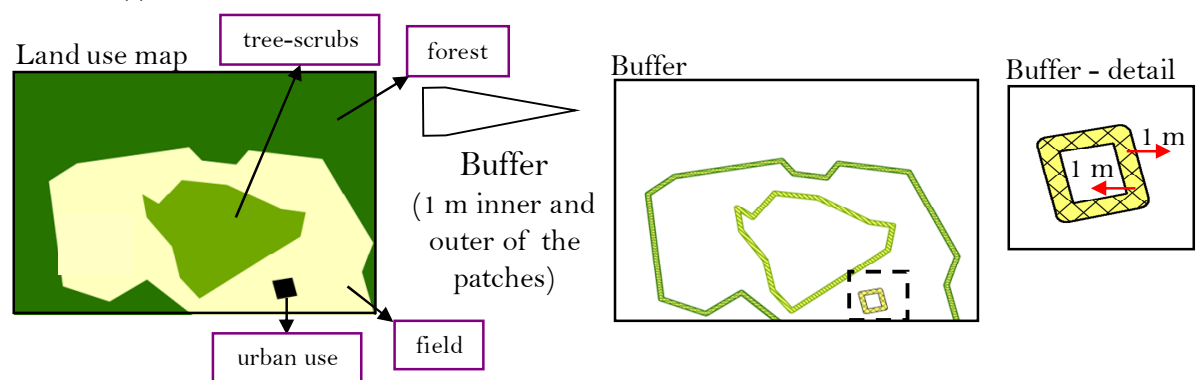

\section{Reclassify}
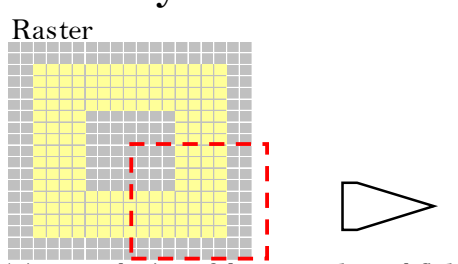

(1) Boundaries of human-altered field
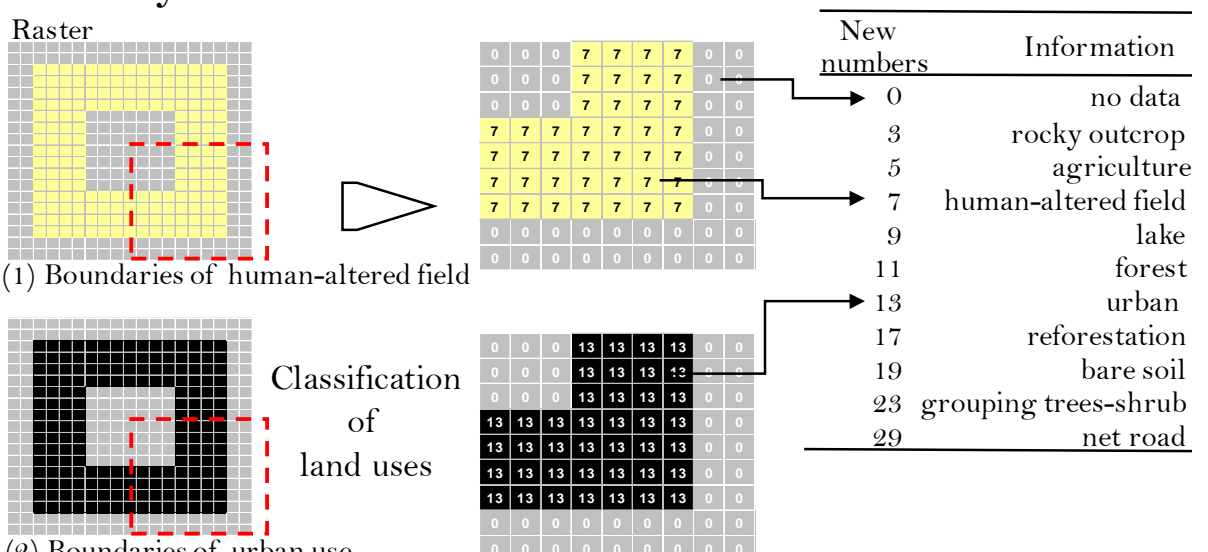

(2) Boundaries of urban use

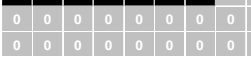

\section{Raster calculator}

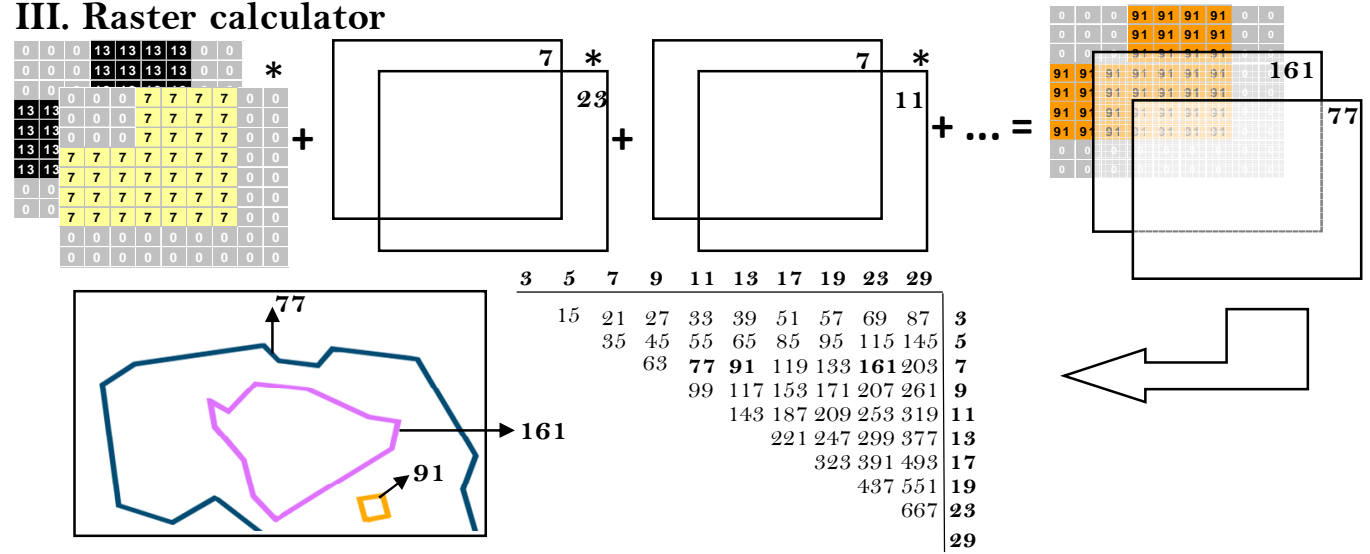

Figure 1. Boundary detection for land use/cover layers in raster format 
Table 1. Stage i) Identification and characterization of boundaries using ArcGis® 10.3

\begin{tabular}{|c|c|c|}
\hline \multicolumn{3}{|c|}{ A) For boundary mapping in raster format } \\
\hline \multicolumn{2}{|l|}{ Action } & Commands \\
\hline \multicolumn{2}{|c|}{$\begin{array}{l}\text { I. Create layers of patch edges for each land } \\
\text { use/cover type using polygon internal and } \\
\text { external dilation (Fig. 1.I Buffer Wizard). This } \\
\text { action allows adjacent patches to be superposed } \\
\text { in the next step. }\end{array}$} & $\begin{array}{l}\Rightarrow \text { in ArcMap: Customize > Commands > } \\
\text { Categories: Tools > Commands: Buffer wizard } \\
\text { [select a "use type layer" > Next > Distance units } \\
\text { are: meters > At a specific distance: } 1 \text { meters }> \\
\text { Next > Dissolve barriers between buffers: No > } \\
\text { Create buffer so they are inside and outside the } \\
\text { polygon }(s)>\text { In a new layer, specify output } \\
\text { shapefile }>\text { Finish] } \\
\Rightarrow \text { Repeat this procedure for all use types }{ }^{1}\end{array}$ \\
\hline \multicolumn{2}{|c|}{$\begin{array}{l}\text { II. Identification of edge types between patches } \\
\text { using codes classify of layers into prime numbers } \\
\text { (Fig. 1.II Reclassify). }{ }^{2}\end{array}$} & $\begin{array}{l}\Rightarrow \text { in ArcToolbox: Spatial Analyst Tools > } \\
\text { Reclass > Reclassify [select a "buffer output" as } \\
\text { Input raster > Reclass field: select Value > } \\
\text { Classify > New values: input the new number and } \\
0 \text { to NoData > Name the Output raster }>\text { OK] } \\
\Rightarrow \text { Repeat this procedure for all use types }{ }^{1}\end{array}$ \\
\hline \multicolumn{2}{|c|}{$\begin{array}{l}\text { III. Multiplication of pairs of layers reclassified } \\
\text { by superposition and the sum of all the resulting } \\
\text { layers (Fig. 1.III Raster Calculator). The } \\
\text { calculation allows the type of boundary between } \\
\text { patches to be described because the multiplication } \\
\text { of prime numbers always results in unique } \\
\text { combinations. }\end{array}$} & $\begin{array}{l}\Rightarrow \text { in ArcToolbox: Spatial Analyst Tools Map } \\
\text { Algebra }>\text { Raster Calculator [create an } \\
\text { expression like this ([layer_use1] } * \text { [ layer_use2] }) \\
+([\text { layer_use1] } * \text { [layer_use3]) }+\ldots+([\text { layer_use } \\
\text { n-1]* [layer_use n]) }>\text { Name output raster as } \\
\text { "boundarymap" > Evaluate] } \\
\Rightarrow \text { Exclude the combinations that are different } \\
\text { from expected }\end{array}$ \\
\hline \multicolumn{3}{|c|}{ B) For boundary mapping in vector format } \\
\hline \multicolumn{2}{|l|}{ Action } & Commands \\
\hline \multicolumn{2}{|c|}{ I. Same as for the raster technique (Fig. 1.I). } & Same as for the raster technique \\
\hline \multicolumn{2}{|c|}{$\begin{array}{l}\text { II. Superposition of all pairs of boundary layers } \\
\text { between land use/cover patches generated in the } \\
\text { previous stage for the identification of } \\
\text { boundaries. }\end{array}$} & $\begin{array}{l}\Rightarrow \text { in ArcToolbox: Analysis Tools }>\text { Overlay }> \\
\text { Intersect [Input features: add } 2 \text { types of "buffer } \\
\text { output" > Name the output feature class }>\text { OK] } \\
\Rightarrow \text { Repeat this tool for all combinations of buffer } \\
\text { layers }\end{array}$ \\
\hline $\begin{array}{l}\text { Ex. of land use } \\
\text { uses } \\
\text { urban } \\
\text { field } \\
\text { forest }\end{array}$ & \begin{tabular}{lll}
\multicolumn{3}{c}{ cover combinations: } \\
urban & field & forest \\
- & urb-fie & urb-for \\
- & - & fie-for \\
- & - & - \\
\end{tabular} & \\
\hline \multicolumn{2}{|c|}{$\begin{array}{l}\text { III. Denomination of boundary types for each } \\
\text { resulting layer in the previous step to merge them } \\
\text { in a single file. }\end{array}$} & $\begin{array}{l}\Rightarrow \text { in ArcMap: Open Attribute Table of a "buffer } \\
\text { intersect output" > Table Options > Add Field } \\
\text { [Name the new field as "boundary" > Type: text] } \\
>\text { Editor > Start Editing > Attribute table } \\
\text { [include the boundary type in the new field > } \\
\text { Explode Multi-part feature > Save edits] } \\
\Rightarrow \text { Repeat this procedure for all boundary types }{ }^{1} \\
\Rightarrow \text { In ArcToolbox: Data Management Tools > } \\
\text { General > Merge [Input as Dataset all "buffer } \\
\text { intersect output" > name the output dataset as } \\
\text { "boundary map" > Field map: keep the new field } \\
\text { only > OK] }\end{array}$ \\
\hline
\end{tabular}

${ }^{1}$ Batch automation or the "Line Window" command can be used to speed up the repetition process

${ }^{2}$ It precedes the conversion of original vector buffer layers into raster format 
The proceeding starts by including in each layer the fields in which the boundary presence-absence, frequency or length will be registered (Table 2-I). The new file must be superposed with the land use/cover map, and the boundaries can be identified (Table 2-II). Attention should be given to deleting any superposition that exceeds a twoby-two combination.

In the next step, the matrix of patches $\times$ boundaries is reorganized (Table 2-III) to calculate the presence-absence, frequency or length of all the boundaries of each patch (Table 2-IV).

\section{Stage 3 - Identifying and mapping mosaics}

This stage begins by using the multivariate analysis of the patches $\times$ boundaries matrix to identify the landscape mosaics. The matrix is exported to statistical software such as SPSS (Table 3-I) and submitted to multivariate ordination and clustering analyses (Table 3-II) based on the method developed by Roldán et al. (2003, 2006).

Table 2. Stage ii) Development of patch $\times$ boundary matrices using ArcGis® 10.3

\begin{tabular}{|c|c|c|c|c|}
\hline \multicolumn{4}{|l|}{ Action } & Commands \\
\hline \multicolumn{4}{|c|}{$\begin{array}{l}\text { I. Preparation of boundary layers for subsequent boundary } \\
\text { measure registration. }\end{array}$} & $\begin{array}{l}\Rightarrow \text { in ArcMap: Open Attribute Table of } \\
\text { "boundary map" > Table Options > Add } \\
\text { Field [Name the new field > Type: long } \\
\text { integer] > Editor > Start Editing > } \\
\text { Attribute table [ } \\
\text { a) For the presence/absence frequency: } \\
\text { attribute value (1) for the new field } \\
\text { created as "count"; } \\
\text { b) For the length: right click on the new } \\
\text { field created as "length" < Field } \\
\text { Calculator "length" = [Area]/2 } \\
>\text { Save edits] }\end{array}$ \\
\hline \multicolumn{4}{|c|}{$\begin{array}{l}\text { II. Superposition of the land use/cover map with the } \\
\text { boundary map for the identification of the boundary types } \\
\times \text { land use/cover patch. }\end{array}$} & $\begin{array}{l}\Rightarrow \text { in ArcToolbox: Analysis Tools > } \\
\text { Overlay > Spatial Join [Target features: } \\
\text { "use map" > Join features: "boundary } \\
\text { map" > Name the output feature class > } \\
\text { Join operation: join one to many > Field }\end{array}$ \\
\hline ID use & boundary & join count & length & map of join features: "use map" (ID, use \\
\hline 1 urban & URB-FIE & 1 & 10 & type); "boundary map" (boundary, count, \\
\hline 1 urban & URB-FOR & 1 & 22 & length) $>$ OK] \\
\hline 1 urban & URB-LAK & 1 & 9 & $\begin{array}{l}\Rightarrow \text { In ArcMap }- \text { correction of } \\
\text { superposition errors: Start Editing }>\end{array}$ \\
\hline$\ldots$ & & & & $\begin{array}{l}\text { Selection > Select by Attributes [Layer: } \\
\text { "spatial join output" > Method: Create a } \\
\text { new selection > "use type" = "usel" > } \\
\text { Ok] > Selection > Select by Attributes } \\
\text { [Layer: "spatial join output" > Method: } \\
\text { Remove from current selection > } \\
\text { ("boundary" = "boundaryl" OR } \\
\text { "boundary" = "boundary2" } \\
\text { "boundary" = all combinations types for } \\
\text { "usel")] > Press Delete } \\
\Rightarrow \text { Repeat this correction for all use } \\
\text { types* }\end{array}$ \\
\hline
\end{tabular}


III. Reorganization of the boundaries table by land use/cover patches.

Example of tables created in this step:

a) For the presence/absence and frequency

\begin{tabular}{|l|l|l|c|c|c|c|c}
\hline ID & use & boundary & join & URB- & URB- & URB- & \\
count & FIE & FOR & LAK & $\cdots$ \\
\hline 1 & urban URB-FIE & 1 & 1 & 0 & 0 & \\
\hline 1 & urban URB-FOR & 1 & 0 & 1 & 0 & \\
\hline 1 & urban URB-LAK & 1 & 0 & 0 & 1 & \\
\hline $\mathrm{n}$ & $\ldots$ & & & & & \\
\hline
\end{tabular}

b) For the length

\begin{tabular}{l|l|l|l|c|c|c|c}
\hline ID & use & boundary & length & $\begin{array}{c}\text { URB- } \\
\text { FIE }\end{array}$ & $\begin{array}{c}\text { URB- } \\
\text { FOR }\end{array}$ & $\begin{array}{c}\text { URB- } \\
\text { LAK }\end{array}$ & $\cdots$ \\
\hline 1 & urban & URB-FIE & 10 & 10 & 0 & 0 & \\
\hline 1 & urban & URB-FOR & 22 & 0 & 22 & 0 & \\
\hline 1 & urban & URB-LAK & 9 & 0 & 0 & 9 & \\
\hline $\mathrm{n}$ & $\ldots$ & & & & & & \\
\hline
\end{tabular}

IV. Summary of boundary attributes by patch ID.

Examples of patch $\times$ boundary matrices:

a) For presence/absence

\begin{tabular}{l|l|c|c|c|}
\hline ID & use & MAX $_{\text {URB-FIE }}$ & MAX $_{\text {URB-FOR }}$ & $\ldots$ \\
\hline 1 & urban & 1 & 1 & \\
\hline 2 & field & 1 & 0 & \\
\hline 3 & forest & 0 & 1 & \\
\hline $\mathbf{n}$ & $\ldots$ & & & \\
\hline
\end{tabular}

b) For frequency

\begin{tabular}{ll|c|c|c}
\hline ID & use & SUM $_{\text {URB-FIE }}$ & SUM $_{\text {URB-FOR }}$ & $\ldots$ \\
\hline 1 & urban & 5 & 3 & \\
\hline 2 & field & 1 & 0 & \\
\hline 3 & forest & 0 & 11 & \\
$\mathrm{n}$ & $\ldots$ & & & \\
\hline c) & For length & & & \\
\hline ID & use & SUM $_{\text {URB-FIE }}$ & SUM $_{\text {URB-FOR }}$ & $\ldots$ \\
\hline 1 & urban & 10 & 22 & \\
\hline 2 & field & 18 & 0 & \\
\hline 3 & forest & 0 & 4 & \\
\hline $\mathrm{n}$ & $\ldots$ & & & \\
\hline
\end{tabular}

$\Rightarrow$ in ArcToolbox: Data Management Tools > Table > Pivot Table [Input table: "spatial join output" > Input fields: all attribute fields $>$ Pivot field: "boundary" > Value field:

a) For the presence/absence and frequency: select the "count" field;

b) For the length: select the "length" field

$>$ Name the output table $>\mathrm{OK}]$

$\Rightarrow$ in ArcToolbox: Analysis tools > Statistics > Summary Statistics [Input table: select a "pivot table output" > Name the output table > Statistics field(s): include all boundary types) > Statistic type:

a) For presence/absence: MAX - for value field (1) > Case field: ID

b) For frequency: SUM - for value field (1) > Case field: ID

c) For length: SUM - for value field "length" > Case field: ID

$>\mathrm{OK}]$

Patches with similar coordinates on the ordination axes have similar boundary pattern and consequently may be regarded as belonging to the same mosaic. To better identify these groups, patches are also clustered according to their coordinates on the ordination axes (Roldán et al., 2003). Each of the identified clusters corresponds to a mosaic. The mosaic to which each patch corresponds is recorded in a table. The table is 
incorporated into ArcGis ${ }^{\circledR}$ to map the mosaics (Table 3-III). This step is performed by joining the table with the land use/cover map in accordance with the patch number register (ID). This allows the mosaics to be mapped, as presented in Hardt et al. (2013).

Table 3. Stage iii) Identification and mapping of landscape mosaics

\begin{tabular}{|c|c|}
\hline Action & Commands \\
\hline $\begin{array}{l}\text { I. Export the table of patches } \times \text { boundaries from } \\
\text { ArcGIS }^{\circledR} \text { to statistical software. }\end{array}$ & $\begin{array}{l}\Rightarrow \text { in any Statistical software: Open the *.dbf } \\
\text { corresponding to the output table obtained in the } \\
\text { last step of stage ii). } \\
\text { For example, SPSS software opens directly the } \\
* \text {.dbf file generated by ArcGis }{ }^{\circledR} 10.3 \text {. }\end{array}$ \\
\hline $\begin{array}{l}\text { II. Mosaics identification: } \\
\text { a) DCA analysis of the patches } \times \\
\text { boundaries table; } \\
\text { b) Cluster analysis of the patches according } \\
\text { to their scores on the DCA axes. }\end{array}$ & $\begin{array}{l}\Rightarrow \text { in the statistical software selected: Start from } \\
\text { one of the boundary measures recorded in the } \\
\text { output table and subject the selection (patches } \\
\text { selected boundary measure) to the DCA and } \\
\text { cluster analysis. See Roldán et al. }(2003,2006) \text { for } \\
\text { details. } \\
\text { The final step is to build a table of patches } \times \\
\text { cluster number. This new table contains the } \\
\text { number of the cluster or mosaic corresponding to } \\
\text { each patch. }\end{array}$ \\
\hline $\begin{array}{l}\text { III. Mosaic mapping in ArcGIS }{ }^{\circledR} \text { by joining the } \\
\text { land use/cover map with the cluster table created } \\
\text { in the last step, followed by a new representation } \\
\text { of the patches using cluster numbers that identify } \\
\text { the mosaics. }\end{array}$ & $\begin{array}{l}\Rightarrow \text { in ArcMap: Insert the new table of patches } \times \\
\text { cluster number > Add Data [ "new table" > Add } \\
>\text { Save] > mosaic mapping by right clicking on } \\
\text { the land use/cover map > Joins and Relates > } \\
\text { Join [Join attributes from a table > Field layer } \\
\text { join based on: "ID" > Table to join: "new table" > } \\
\text { Field table join on: "ID" > OK] > attribute the } \\
\text { mosaic's symbology by right clicking on the land } \\
\text { use/cover map > Properties > Symbology } \\
\text { [Categories > Value Field: "cluster number" > } \\
\text { Add all values > OK]. }\end{array}$ \\
\hline
\end{tabular}

The instructions shown in Tables 1 and 2 refer to ArcGis ${ }^{\circledR}$, but the sequence of operations may also be implemented in another GIS using the tools corresponding to each of the operations described in detail.

\section{Example of the methodological procedure}

The validity of the method for the three types of boundary measures was tested for a case study in Serra do Japi (São Paulo, Brazil) by comparing the mosaics' complexity results with the local reality aided by the statistical analysis described below. This study case used part of a database developed to describe the utility of landscape mosaics for decision making for Atlantic Forest conservation. Additional details of this analysis can be found in Hardt et al. (2013).

The land use/cover map (Appendix A) shows the spatial distribution of 3,979 patches corresponding to ten land uses/covers (Appendix B) that have 30,057 boundaries of 37 distinct types. Three matrices of patches $\times$ boundaries were calculated using of presence/absence, frequency or length boundary data for each patch. 
Each matrix was subjected to a Detrended Correspondence Analysis (DCA; Hill, 1981) using PC-Ord ${ }^{\circledR} 4.0$ software. The scattergrams of the boundaries and patches according to axes 1-2 and 2-3 of the three DCA are shown in Fig. 2. The patches were then clustered according to their coordinates on the first three axes of the DCA using a free trial version of $\mathrm{XIStat}^{\circledR}$. The clustering was performed by applying Ward's method as the amalgamation algorithm and Euclidean distance as the measure of similarity (Fig. 3).

The group similarity cut-off level in the dendrograms was standardized at $95 \%$. The clusters were characterized according to their boundaries by means of Chi-square analyses for the presence/absence data and Student's t-test for the frequency and length data. Finally, the patch clusters were incorporated into the ArcGis ${ }^{\circledR}$ database for mapping the mosaics. Thus, three landscape mosaic maps of the Serra do Japi were drawn (Fig. 3).

The distribution of boundaries and patches in the ordination scattergrams indicates that boundary frequency is the boundary measure that most clearly displays the boundary distribution variability in the sets of patches (Fig. 2c). For the presence/absence (Fig. 2a) and length (Fig. 2d) data, the distribution of these two elements was strongly conditioned by a single type of boundary (between outcrop AFL - and forest - BOS - represented by the AFL-BOS code) with a small number of occurrences in the landscape. This makes the scattering of data in the space defined by the first ordination axis more compact (Figs. $2 a$ and $d$ ), with many of the patches having very similar coordinates. This hinders the interpretation of the variability of boundaries and the recognition of groups of patches, on which the identification of the mosaics is based (Roldán et al., 2003, 2006). It does not occur when frequencies are studied because the frequencies of this boundary do not greatly limit the dispersion of data (Fig. 2c).

To corroborate this result, new scattergrams were drawn by removing the patches with higher coordinates on axis 1, that is, those with positions that were highly dependent on the AFL-BOS boundary. A wider distribution of patches and boundaries was obtained for the presence/absence data (Fig. 2b), but most of them continued to have very close coordinates.

The scattergram of the length matrix (Fig. 2e) shows sets of patches arranged in rows. This indicates that these sets responded to variations in the lengths of one or a few boundaries, which is related to the particular structure of the study area, in which there are large forest patches that are located at high altitudes and are surrounded by small fragments of other anthropic uses (Appendix A). Therefore, the forest patches have more variable perimeter lengths than other land uses/covers. This increases the possibility that forest patches will have boundaries with varied lengths, from very short to very long.

Boundaries that characterize the selected clusters, i.e., the identified mosaics, are also included in the dendrograms obtained from patch clustering (Fig. 3). Both the presence/absence (Fig. 3a) and length (Fig. 3c) data produced dendrograms with a cluster that remained undivided from the first division. In these cases, this cluster is characterized by the AFL-BOS boundary. The dendrogram obtained from the frequency data (Fig. 3b) had a better organized set and sub-set structure because no clusters remained undivided from the first division. These results agree with those obtained from the ordination scattergrams because the boundary frequency data provided a more easily understandable interpretation and did not uniquely depend on the spatial distribution or length of just one boundary. 
a)

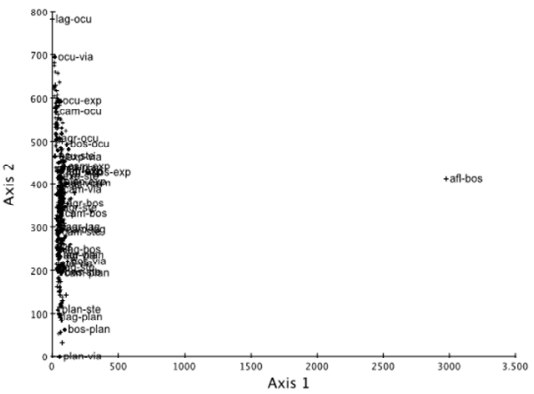

b)

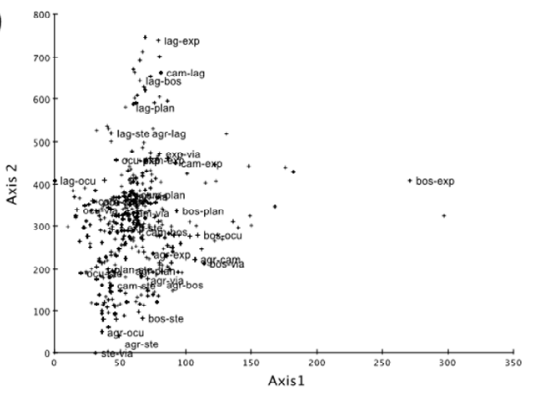

c)

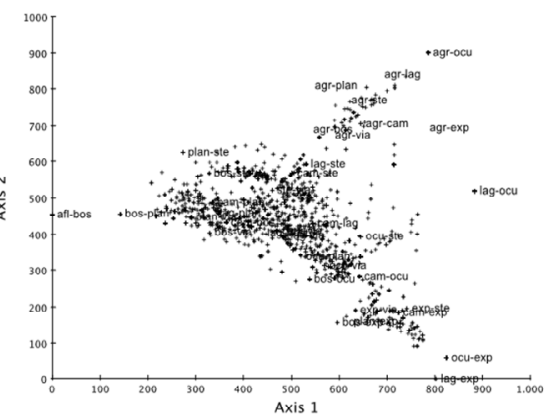

d)

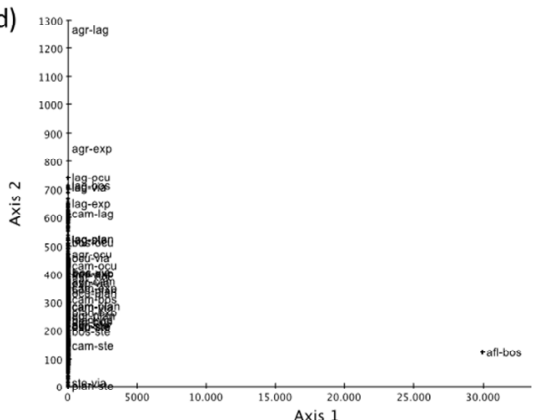

e)

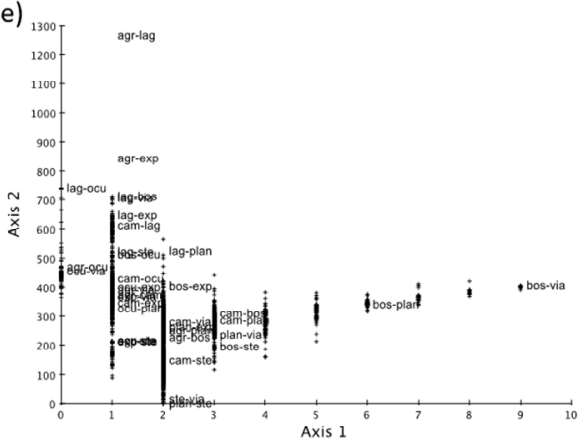

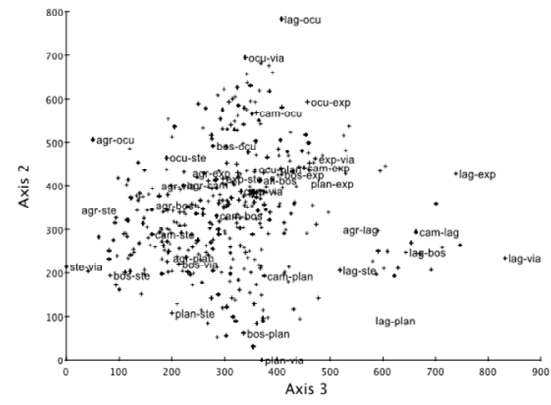
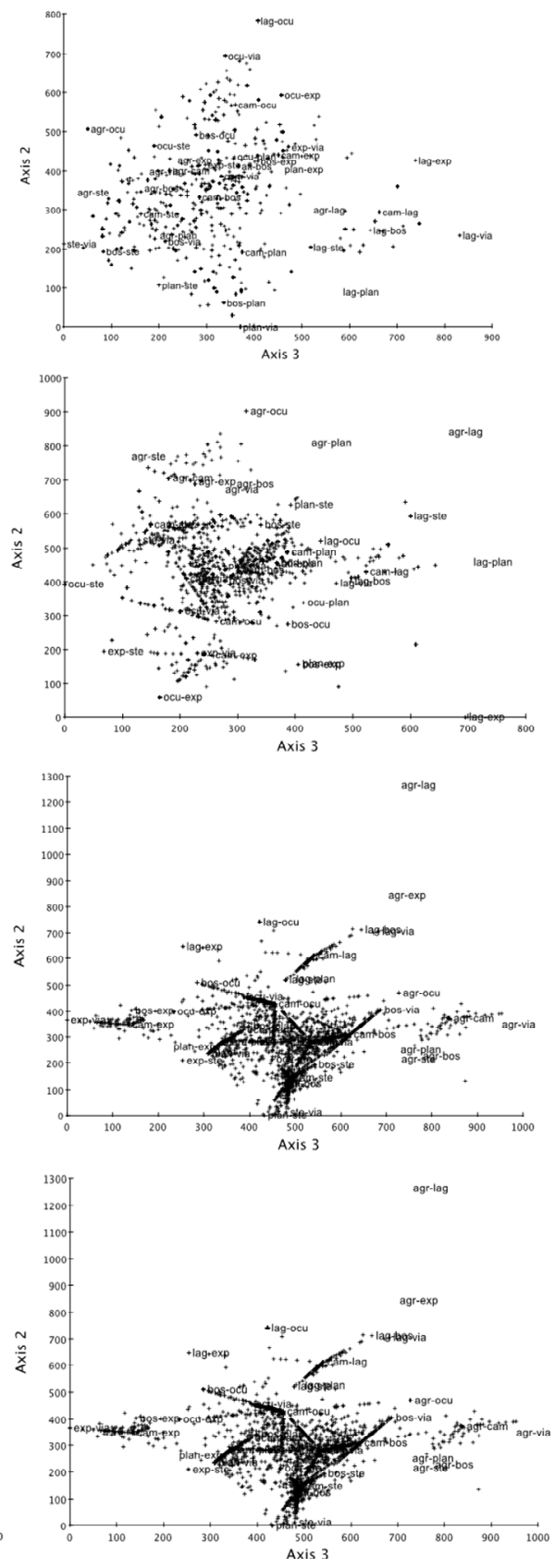

Figure 2. Results of the DCA ordination of patch $\times$ boundary matrices. Scattergrams for axes 1 and 2 and axes 2 and 3 of a) the presence/absence matrix, $b$ ) the presencelabsence matrix without outliers, $c$ ) the frequency matrix, $d$ ) the length matrix, and e) the length matrix without outliers. Patches are represented by crosses, and boundaries are represented by abbreviations of the land use/cover codes, which are presented in Appendix B 
a)

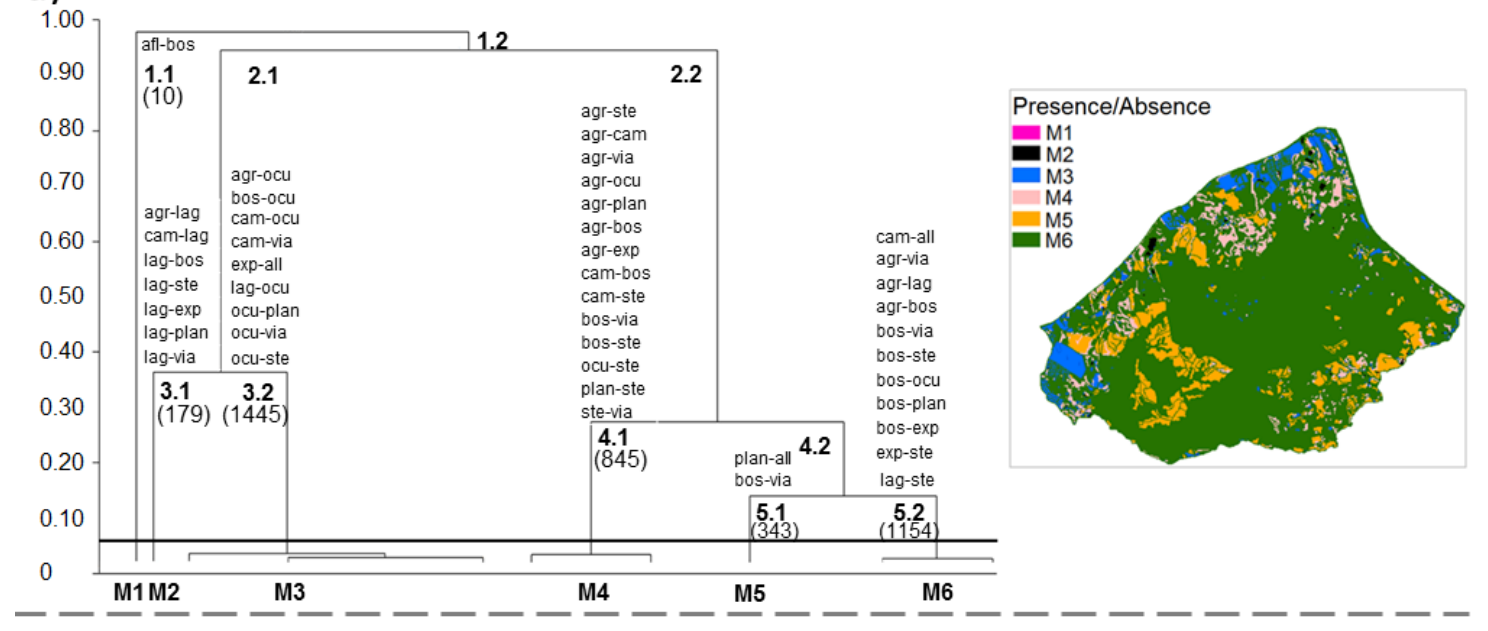

b)
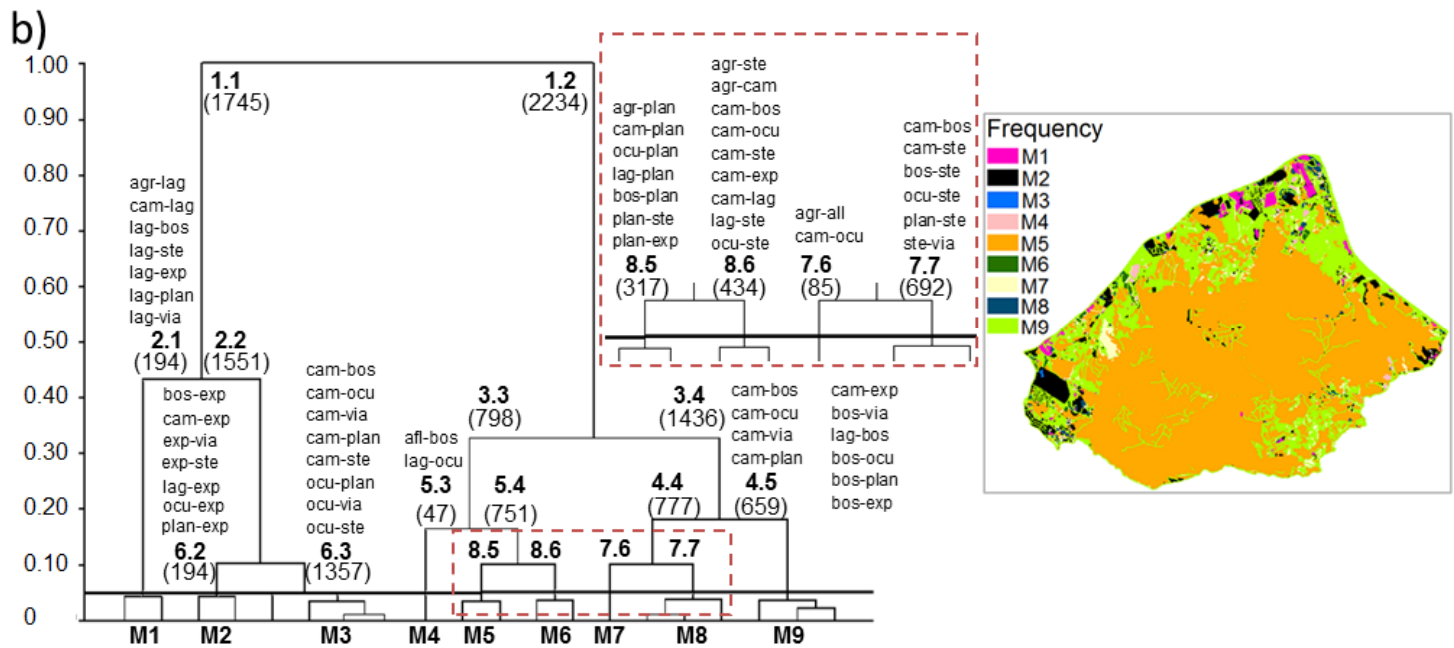

c)
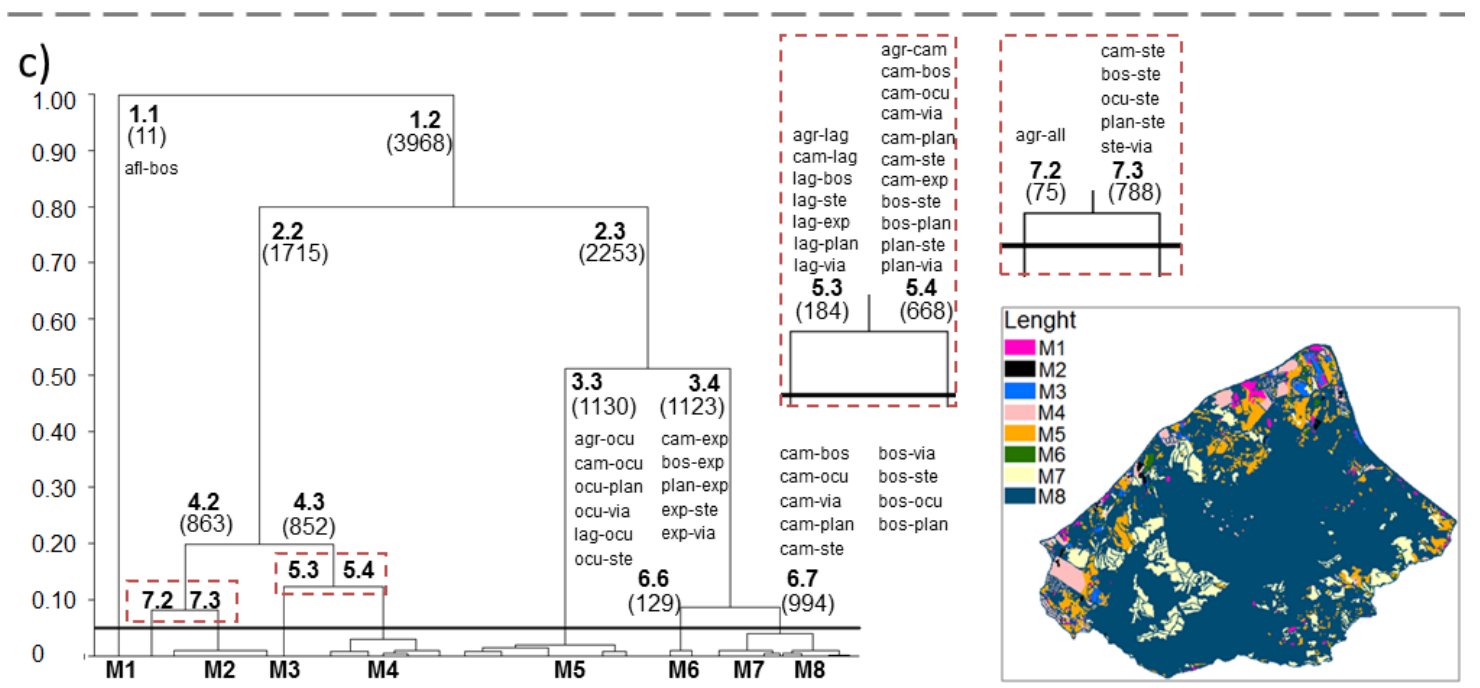

Figure 3. Clustering results of patches in mosaics (I) and the corresponding mosaic map (II) obtained from data on boundary presencelabsence $(a)$, frequency $(b)$ and length $(c)$

A large central mosaic and a more heterogeneous peripheral landscape is identified in all the mosaic maps, irrespective of the boundary measure used (Fig. 3). These 
results agree with that reported by Hardt et al. (2013) on the landscape spatial structure in the same study area. This indicates that the differences in the results obtained using the three boundary measures depend on the different landscape details highlighted by each measure.

In summary, in this example, boundary frequency is the boundary measure that most clearly allows us to identify mosaic-patch sets with a similar boundary pattern (Figs. $2 c$ and $3 b$ ). The frequency distribution of boundaries did not seem to be highly conditioned by the low frequencies of some of them, which were present only in some patches, as seemed to be case for the presence/absence measure. In addition, the sizes of the patches were less important for the frequency measure because that variable had a lower variation rank than the length measure.

\section{Discussion}

Building matrices of patches $\times$ boundaries has been the constraining factor in landscape mosaic mapping. Methodological procedures like the one described, which is the only one known by the authors, allows these matrices to be easily drawn up, thus contributing to operationalizing the concept of landscape mosaics and making its application in landscape management possible (Hardt et al., 2013; Bertolo et al., 2015; Martín de Agar et al., 2016). The procedure has also the advantage of using standard GIS and statistical software.

The procedure developed permits input land use/cover maps in both raster and vector formats to be used. It works practically without limitation to large datasets, depending only on the software used and on the available memory and system cache of the user's computer. The implementation of this concept has previously been limited by the difficulty when working with large territories, which probably explains the small number of studies on the complexity of landscape interactions based on mosaics (Cantwell and Forman, 1993; Roldán-Martín et al., 2003, 2006; Hersperger, 2006) and their use in environmental planning and management (Hardt et al., 2013; Bertolo et al., 2013).

Each boundary measure provides a particular interpretation of landscape organization, and researchers must therefore evaluate the measures that best meet their objectives. In the example, the mosaics identified using boundary presence/absence was not the most revealing of the landscape variability. The qualitative aspect seems to be a large constraint, as the occurrence of a low presence boundary conditioned the results by impeding the easy observation of other patterns.

In our example, when mosaics are characterized by boundary length, the information provided was apparently influenced in both qualitative aspects as related to very low frequency boundaries (Fig. 2d) and patch size (Fig. 2e). This is the case of large forest patches having boundaries of all lengths. They condition the patch arrangement "in lines" (Fig. 2e), depending mainly on the differences in the lengths of the boundaries and less on their natures. The large forest patches conditioned the dispersion of the others in the DCA, primarily because of they may have boundaries of different lengths, which condition the identification of mosaics.

Boundary identification is closely related to the degree of landscape fragmentation and connectivity (Metzger and Muller, 1996; Rescia et al., 1997; Collinge and Forman, 1998; Trani and Giles, 1999; Zeng and Ben Wu, 2005). However, when a landscape becomes more fragmented, the boundary frequencies tends to provide information about 
the fragmentation pattern that cannot be derived from length (Zeng and Ben $\mathrm{Wu}, 2005$ ). Boundary frequency enable reporting stages prior to the rupture of the landscape based on the identification of patch perforations (Forman, 1995). Because of that ability, mosaics identified by frequency boundaries are apparently important in assessing the history of fragmentation pressures, understanding rupture dynamics over time and even indicating probable future scenarios (Hardt et al., 2013).

In our example, the relative similarities among the three mosaic maps (Fig. 3) could have been due to landscape homogeneity (Corbacho et al., 2000) explained by the small fragmentation in the central area and the large fragmentation in the peripheral areas.

Measures of boundaries such as frequency and length respond to spatial pattern in landscape heterogeneity (Metzger and Muller, 1996) and are particularly sensitive to environmental changes (Fortin et al., 2000). In that sense, mosaic landscape organization models should reflect depth spatial heterogeneity in such a way that they clearly show patterns of ecological interactions and landscape complexity (Lovett et al., 2005; Roldán-Martín et al., 2006; Hardt et al., 2013).

There are other models that describe the influences of spatial pattern on ecological processes and their changes over time, including the well-known patch-corridor-matrix model (Forman, 1995). However, that model is limited in its ability to detect landscape spatial heterogeneity, which can lead to errors in decision-making for landscape management (Hardt et al., 2013)

The described method has many possible practical outputs that could assist decision making in landscape management, for example, comparisons between mosaics built from historical maps, which record landscape changes, highlight driving forces and change vectors. These affect land cover/use and boundaries. New mosaics can appear as the result of changes in boundaries as well as land cover/uses, as reported by Hardt et al. (2013). For that reason, this analysis permits future scenarios to be proposed for nature conservation that have different degrees of human interference, keeping in mind that in landscapes with less complex spatial interactions and mosaics with simpler boundary structures, management is easier. Mosaics can also be used to identify priority areas for conservation according to the types and complexities of neighborhood spatial relationships, including the definition of appropriate management actions in accordance with them.

Due to their capabilities, mosaics can be used as units of landscape organization (Wiens, 1999; Hersperger, 2006) to identify territories that differ in structure, function, and forest conservation status (Hardt et al., 2013). In this way, mosaics can be a key tool to identify action zones for environmental planning and management, where planners and decision makers need to analyze the consequences on ecosystem service provision, especially in regions that face complex environmental issues and where natural resources share space with anthropic uses.

\section{Conclusions}

The methodological procedure contributes to making the concept of landscape mosaics more operative and applicable for environmental planners.

The procedure works with any size area, with large data sets and in automated processes. However, the usefulness of the different boundary measures should be assessed in accordance with landscape characteristics and study purpose. 
The case study highlights the influence of landscape homogeneity and fragmentation on the similarities among mosaics that are obtained by different boundary attributes. It also differentiated boundary frequency as the attribute that can be used to more easily identify and interpret mosaics due to its capacity to interpret the dynamics of landscape rupture patterns.

Acknowledgements. This work was supported by the FAPESP-BR [grant number 06/55385-0; 08/015050, the CAPES-BR and Fundación Carolina-ES [grant number BEX 3967/10-7], the Santander/UCM-ES group [grant mobility 2011] and the Ministry of Science and Innovation-ES [grant MA-2012].

\section{REFERENCES}

[1] Banerjee, S., Carlin, B. P., Gelfand, A. E. (2015): Hierarchical Modelling and Analysis for Spatial Data. - CRC Press/Chapman \& Hall, Boca Raton.

[2] Bastian, O., Grunewald, K., Khoroshev, A. V. (2015): The significance of geosystem and landscape concepts for the assessment of ecosystem services: exemplified in a case study in Russia. - Landscape Ecology 30: 1145-1164.

[3] Bertolo, L. S., Santos, R. F., Martín de Agar, P., De Pablo, C. T. L. (2015): Land-use changes assessed by overlay or mosaic methods: which method is best for management planning? - Ecological Indicators 55: 32-43.

[4] Cadenasso, M. L., Pickett S. T. A., Weathers, K. C., Jones, C. G. (2003): A framework for a theory of ecological boundaries. - BioScience 53: 750-758.

[5] Cantwell, M. D., Forman, R. T. T. (1993): Landscape graphs: ecological modeling with graph theory to detect configurations common to diverse landscapes. - Landscape Ecology 8(4): 239-255.

[6] Collinge, S. K., Forman, R. T. T. (1998): A conceptual model of land conversion processes: predictions and evidence from a field experiment with grassland insects. Oikos 82: 66-84.

[7] Corbacho, P. P., Zárate, A., Rebollo, J. C, De Pablo, C. L. (2000): Landscape Homogenisation and Fragmentation: Changes in the Spatial Organisation of the Madrid Landscape (Spain). - In: Brandt, J. B., Tress. B., Tress, G. (eds.) Multifunctional Landscapes: Interdisciplinary Approaches to Landscape Research and Management. Conference on Multifunctional Landscapes. Centre for Landscape Research, Roskilde.

[8] De Groot, R. S., Alkemade R., Braat L., Hein L., Willemen L. (2010): Challenges in integrating the concept of ecosystem services and values in landscape planning, management and decision making. - Ecological Complexity 7: 260-272.

[9] De Pablo, C. L., Roldán, M. J., Martín de Agar, P. (2012): Magnitude and significance in landscape change. - Landscape Research 37(5): 571-589.

[10] Fagan, W. F., Fortin, M. J., Soykan, C. (2003): Integrating edge detection and dynamic modeling in quantitative analyses of ecological boundaries. - Bioscience 53: 730-738.

[11] Forman, R. T. T. (1990): Ecological Sustainable Landscapes: the Role of Spatial Configuration. - In: Zonneveld, I. S., Forman, R.T.T. (eds.) Changing Landscapes: An Ecological Perspective. Springer-Verlag, New York.

[12] Forman, R. T. T. (1995): Land mosaics: The Ecology of Landscapes and Regions. Cambridge University Press, Cambridge.

[13] Forman, R. T., Godron, M. (1981): Patches and structural components for a landscape ecology. - BioScience 31(10): 733-740.

[14] Fortin, M. J., Dale, M. R. T. (2005): Spatial Analysis: A Guide for Ecologists. Cambridge University Press, Cambridge. 
[15] Fortin M. J., Olson R. J., Ferson S., Iverson L., Hunsaker C., Edwards G., Levine D., Butera K., Klemas V. (2000): Issues related to the detection of boundaries. - Landscape Ecology 15: 453-466.

[16] Frank, S., Fürst, C., Koschke, L., Makeschin, F. (2012): A contribution towards a transfer of the ecosystem service concept to landscape planning using landscape metrics. Ecological Indicators 21: 30-38.

[17] Gosz, J. R. (1991): Fundamental Ecological Characteristics of Landscape Boundaries. In: Holland, M. M., Risser, P. G., Naiman, R. J. (eds.) Ecotones: The role of Landscape Boundaries in the Management and Restoration of Changing Environments. Chapman \& Hall, New York.

[18] Hardt, E., Dos Santos, R. F., De Pablo, C. L., Martin de Agar, P., Pereira-Silva, E. F. L. (2013): Utility of landscape mosaics and boundaries in forest conservation decision making in the Atlantic Forest of Brazil. - Landscape Ecology 28(3): 385-399.

[19] Hersperger, A. M. (2006): Spatial adjacencies and interactions: neighbourhood mosaics for landscape ecological planning. - Landscape and Urban Planning 77: 227-239.

[20] Jacquez, G. M., Maruca, S., Fortin, M. J. (2000): From Fields to Objects: a review of geographic boundary analysis. - Journal of Geographical Systems 2: 221-241.

[21] Jacquez, G. M., Fortin, M. J., Goovaerts, P. (2008): Preface to the special issue on spatial statistics for boundary and patch analysis. - Environmental and Ecological Statistics 15: 365-367.

[22] Kirchhoff, T., Trepl, L., Vicenzotti, V. (2013): What is Landscape Ecology? An analysis and evaluation of six different conceptions. - Landscape Research 38(1): 33-51.

[23] Lovett, G. M., Jones, C. G., Turner, M. G. Weathers, K. C. (2005): Ecosystem Function in Heterogeneous Landscapes. - Springer, New York.

[24] Maes, J., Teller A., Erhard M. et al. (2013): Mapping and Assessment of Ecosystems and their Services: an Analytical Framework for Ecosystem Assessments under Action 5 of the EU Biodiversity Strategy to 2020. - Publications Office of the European Union, Luxembourg.

[25] Margalef, R. (1979): The organization of space. - Oikos 33: 152-159.

[26] Martín de Agar, P., Ortega, M., De Pablo, C. L. (2016): A procedure of landscape services assessment based on mosaics of patches and boundaries. - Journal of Environmental Management 180: 214-227.

[27] Metzger, J. P., Müller, E. (1996): Characterizing the complexity of landscape boundaries by remote sensing. - Landscape Ecology 11: 65-77.

[28] MEA, Millennium Ecosystem Assessment (2005): Ecosystems and Human Well-Being: Synthesis. - Island Press, Washington.

[29] Peters, D. P. C., Gosz, J. R., Pockman, W. T., Small, E. E., et al. (2006): Integrating patch and boundary dynamics to understand and predict biotic transitions at multiple scales. Landscape Ecology 21: 19-33.

[30] Morellato, L. P. C. (1992): História natural da Serra do Japi: ecologia e preservação de uma área florestal no sudeste do Brasil (Natural History of the Serra do Japi: Ecology and Preservation of a Forest Area in Southeastern Brazil). - Editora da Unicamp, Campinas.

[31] Rescia, A. J., Schmitz, M. F., Martín de Agar, P., De Pablo, C. L., Pineda F. D. (1997): A fragmented landscape in northern Spain analyzed at different spatial scales: implications for management. - Journal of Vegetation Science 8: 343-352.

[32] Roldán, M. J. R., De Pablo, C. T. L., Martín de Agar, P. (2003): Landscape Mosaics Recognition and Changes Over Time: A Methodological Approach. - In: Mander, U., Antrop, M. (eds.) Multifunctional Landscapes: Continuity and Change. Wit Press, Boston.

[33] Roldán, M. J. R., De Pablo C. T. L., Martín de Agar, P. (2006): Landscape changes over time: comparison of land uses, boundaries and mosaics. - Landscape Ecology 21: 10751088 . 
[34] TEEB (2010): The Economics of Ecosystems and Biodiversity Ecological and Economic Foundations. - Pushpam Kumar, Earthscan, London and Washington.

[35] Trani, M. K., Giles Jr., R. H. (1999): An analysis of deforestation: metrics used to describe pattern change. - Forest Ecology and Management 114: 459-470.

[36] Turner, M. G. (1989): Landscape ecology: the effect of pattern on process. - Annual Review of Ecology, Evolution, and Systematics 20: 171-179.

[37] Urban, D. L., O’Neill, R. V., Shugart, H. H. (1987): Landscape ecology. - BioScience 37: 119-127.

[38] Wiens J. A. (1999): The Science and Practice Landscape Ecology. - In: Klopatek, M., Gardner, R. H. (eds.) Landscape Ecological Analysis: Issues and Applications. Springer, New York.

[39] Wiens, J. A. (2002): Riverine landscapes: taking landscape ecology into the water. Freshwater Biology 47: 501-515.

[40] Wiens, J. A., Crawford, C. S., Gosz, J. R. (1985): Boundary dynamics: a conceptual framework for studying landscape ecosystems. - Oikos 45: 421-427.

[41] Wiens, J. A, Moss, M. R., Turner, M. G., Mladenoff, D. (2007): Foundation papers in landscape ecology. - Columbia University Press, New Work.

[42] Zeng, H., Ben Wu. X. (2005): Utilities of edge-based metrics for studying landscape fragmentation. - Computers, Environment and Urban Systems 29: 159-178. 


\section{APPENDIX}

Appendix A. Land use/cover map of Serra do Japi, Brazil. Created in ArcGIS ${ }^{\circledR}$ by visual interpretation of aerial orthophotos from 2005. Land uses/covers are described in Appendix $B$

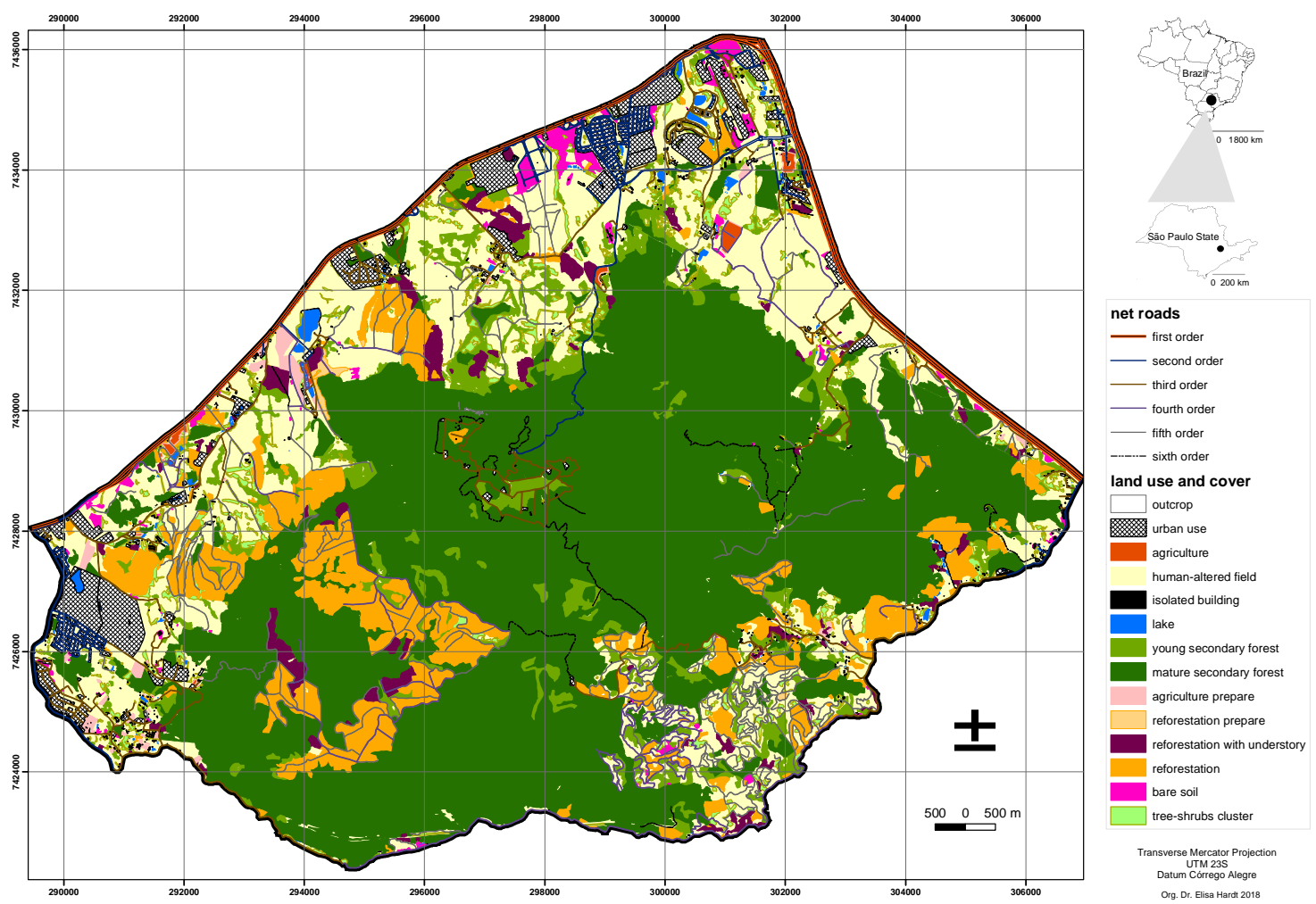


Appendix B. Description and codes of the land use/cover categories identified in Serra do Japi, Brazil

\begin{tabular}{|c|c|c|}
\hline Category & Code & Criterion of classification \\
\hline Rocky outcrop & AFL & Natural open habitat with low vegetation cover \\
\hline Agriculture & AGR & Annual or perennial croplands \\
\hline Human-altered field & CAM & $\begin{array}{l}\text { Pasturelands, abandoned areas (old areas of agriculture and } \\
\text { silviculture), yards, lawns, and wasteland or unused lands }\end{array}$ \\
\hline Bare soil & EXP & Rural or urban areas without vegetation \\
\hline Forest & BOS & Semi-deciduous seasonal forests \\
\hline Lake & LAG & Natural lakes and reservoirs \\
\hline Net road & VIA & Trails, tracks and roads \\
\hline Reforestation & PLAN & Plantations of Eucalyptus spp., Pinus spp. or Araucaria spp. \\
\hline Grouping of trees/shrub & STE & $\begin{array}{l}\text { Patches and corridors of trees and shrubs, natural or human- } \\
\text { modified, without forest structure }\end{array}$ \\
\hline Urban & $\mathrm{OCU}$ & $\begin{array}{l}\text { Urban nuclei and isolated residential, commercial or } \\
\text { industrial buildings }\end{array}$ \\
\hline
\end{tabular}

